Article

\title{
Some New Concepts of Shape Memory Effect of Polymers
}

\section{Abbas Tcharkhtchi ${ }^{1}$, Sofiane Abdallah-Elhirtsi ${ }^{1, *}$, Kambiz Ebrahimi ${ }^{2}$, Joseph Fitoussi ${ }^{1}$, Mohammadali Shirinbayan ${ }^{1}$ and Sedigheh Farzaneh ${ }^{1}$}

1 Laboratoire PIMM, UMR 8006 CNRS, Arts et Métiers ParisTech, Paris 75013, France;

E-Mails: abbas.tcharkhtchi@ensam.eu (A.T.); joseph.fitoussi@ensam.eu (J.F.);

mohammadali.shirinbayan@ensam.eu (M.S.); sedigheh.farzaneh@ensam.eu (S.F.)

2 School of Engineering, University of Bradford, West Yorkshire BD7 1DP, UK;

E-Mail:m.ebrahimi@bradford.ac.uk

* Author to whom correspondence should be addressed; E-Mail: sofiane.abdallah-elhirtsi@ensam.eu; Tel.: +33-1-44-24-61-05.

Received: 8 February 2014; in revised form: 1 April 2014 / Accepted: 2 April 2014 /

Published: 11 April 2014

\begin{abstract}
In this study some new concepts regarding certain aspects related to shape memory polymers are presented. A blend of polylactic acid (PLA) (80\%) and polybutylene succinate (PBS) $(20 \%)$ was prepared first by extrusion, then by injection molding to obtain the samples. Tensile, stress-relaxation and recovery tests were performed on these samples at $70{ }^{\circ} \mathrm{C}$. The results indicated that the blend can only regain $24 \%$ of its initial shape. It was shown that, this partial shape memory effect could be improved by successive cycles of shape memory tests. After a fourth cycle, the blend is able to regain $82 \%$ of its shape. These original results indicated that a polymer without (or with partial) shape memory effect may be transformed into a shape memory polymer without any chemical modification. In this work, we have also shown the relationship between shape memory and property memory effect. Mono and multi-frequency DMA (dynamic mechanical analyzer) tests on virgin and $100 \%$ recovered samples of polyurethane (PU) revealed that the polymer at the end of the shape memory tests regains $100 \%$ of its initial form without regaining some of its physical properties like glass transition temperature, tensile modulus, heat expansion coefficient and free volume fraction. Shape memory (with and without stress-relaxation) tests were performed on the samples in order to show the role of residual stresses during recovery tests. On the basis of the results we have tried to show the origin of the driving force responsible for shape memory effect.
\end{abstract}


Keywords: polymers; shape memory effect; properties memory effect; polyurethane

\section{Introduction}

The capability of the shape memory polymers (SMPs) to remember their initial form under the action of stimulants is attractive in engineering applications. SMPs have a wide range of functions in the design of micro-biomedical components, medical devices, smart textiles, sensors, aerospace deployable equipment, and so on. This has resulted in a growing research interest in this field [1-11].

The ability of SMPs to change form could be programmed in various ways such as thermo mechanical; chemical, electrical and magnetic. Shape memory effects (SME) can be obtained by a process cycle. In the case of heating stimuli, the process can be summarized in successive steps: heating, deformation, relaxation, fixation and recovery.

A review of the literature gives a great deal of valuable information [12-20] about the SMPs; however the answers to a number of serious and foremost questions are still shrouded in mystery. For example, some macroscopic phenomena still lack a detailed understanding on the microscopic level. Thus, there is a need for further fundamental research on SMP and related concepts in order to develop their applications.

The first question is about the definition of SME. Does this effect concern only the macroscopic scale or is it reflected also in the microscopic shape change? In fact, it is usually common to consider SME for macroscopic changes. However, if the capacity to regain the initial (permanent) shape after certain stimulation, even at microscopic scale, is considered as SME, several phenomena like elasticity, shrinkage, swelling, thermal expansion, etc. can also be considered as various expressions of shape memory [21-25]. The definition of SME, in this way, helps us to understand its mechanism more fully on the microscopic and molecular scale. One of the objectives of this work is to demonstrate the importance of this new concept of SME.

The second question concerns the chemical, physical origins of SME and its mechanisms. It is generally accepted that shape memory effect is related to the presence of two different, hard and soft segments in the structure of polymers. The hard morphology stabilizes the permanent shape of the structure while the soft morphology allows the passage from permanent to temporary state or vice versa. In the case of cross-linked polymers, the cross-linkage points and the segments of the chains directly linked to these points may be considered as the hard zones of the morphology. These zones are responsible for the permanent state of the polymer because of their high stability. Moreover, there is no significant molecular motion in these zones. In the case of a blend, the mixture of two themoplastic polymers, one of the polymers (with higher glass transition temperature) may play the role of hard segment and the other one that of soft segment. The compatibility of these two polymers has a high influence. Even though this explanation is correct, it cannot respond to all of the questions related to the SME mechanism; for example it cannot illustrate the chemical and physical origin of SME. So our objective is also to bring in some new elements to explain the mechanism of SME. For example, we try to show the role of driving force during recovery. 
In a study of SMPs one of the questions is about the relationship between SME and properties memory effect (PME). In our previous work [26], we showed that after recovery a SMP does not necessarily exhibit the same properties; that means even after regaining $100 \%$ of initial shape, the polymer may not always show the same properties. In the case of thermal stimuli sensible polymers, one of the ways to determine this relationship is to perform cyclic-thermo-mechanical tests. This investigation can be carried out by means of a tensile machine equipped with a thermo chamber.

Figure 1 shows a three-dimensional demonstration of each cycle. As can be seen, each cycle consists of three consecutive steps, stress-strain curve, stress-relaxation time evolution and recovery.

Figure 1. A tridimensional presentation (stress-time-strain) of one cycle of shape memory tests on polyurethane [26].

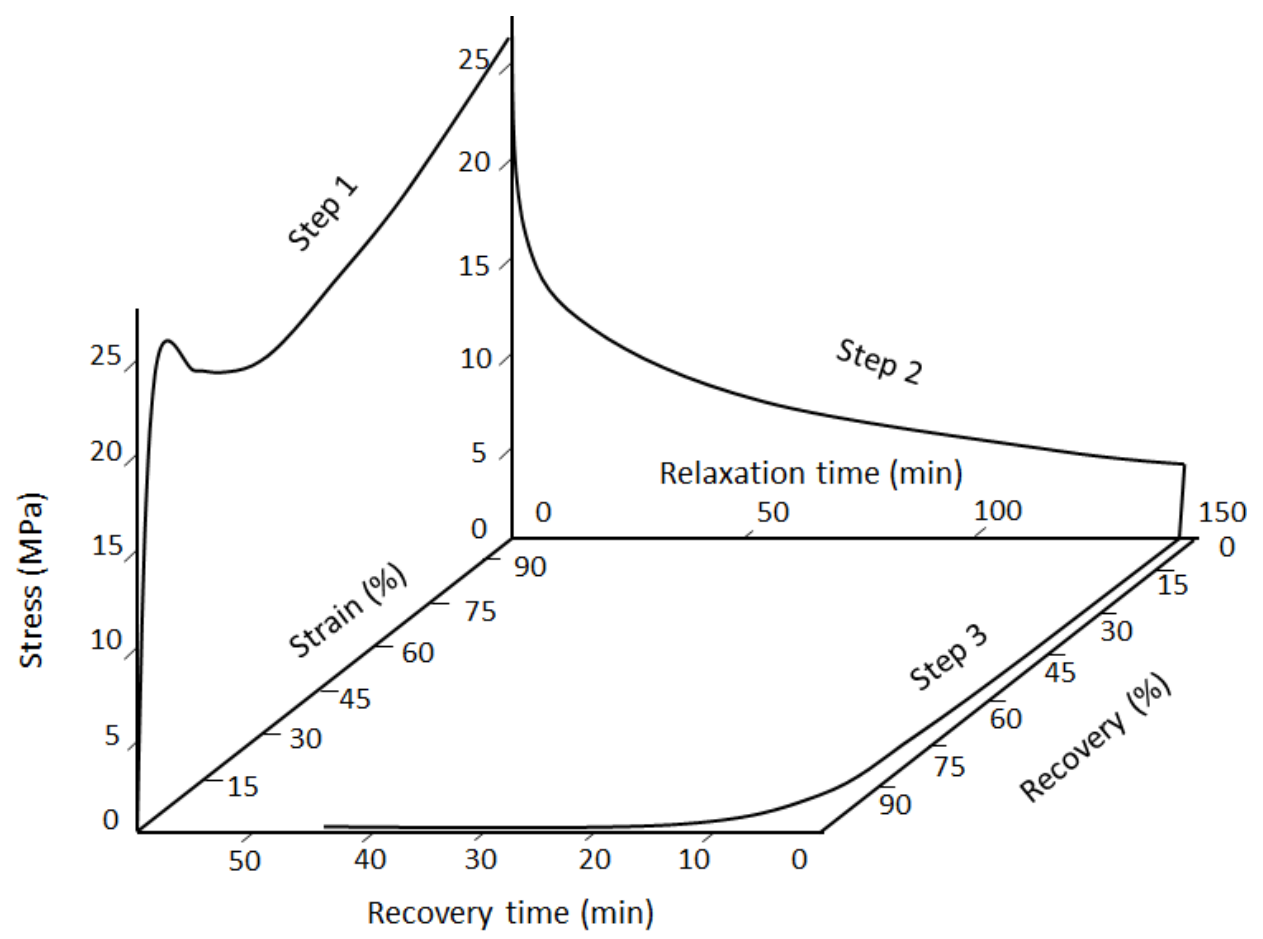

This paper also introduces the concept of partial shape memory effect (PSME). It is worth mentioning that between the SMP and those without SME, there are polymers which have an intermediate behavior. This concept is important because it helps us to understand the difference between an SMP and a non-SMP via the behavior of the polymers with PSME.

\section{Materials}

In this study, two polymers were used: polyurethane (PU) and a blend of polylactic acid (PLA) and polybutylene succinate (PBS), which is one of the most promising polymers in the family of synthetic biodegradable polyesters. The PU exhibits 100\% SME and the PLA/PBS shows PSME.

The blend PLA (80\%)/PBS (20\%) was made with the following polymers:

- Polylactic acid (PLA): PLA, trade name "Ingeo ${ }^{\mathrm{TM}}$ biopolymer 2003D", is a NatureWorks LLC product (Blacksburg, VA, USA). It is a semi-crystalline thermoplastic, used naturally or as part 
of a formulated blend. This is a high molecular weight biopolymer grade that processes easily on conventional extrusion equipment.

- Polybutylene succinate (PBS), trade name PBE002 commercialized by Natureplast (Caen, France) is a kind of fully biobased macromolecular polymer which is synthesized from succinic acid and 1,4-butanediol through a direct process of condensation polymerization.

- The PLA that we used for this study is brittle, however different experiments showed that [27,28], the blend of up to $20 \%$ (by weight) PBS content in PLA is expected to overcome the deficiencies of PLA.

- Polyurethane (PU), supplied by the RAIGI Company (Rouvray-Saint-Denis, France), is the result of the reaction between an isocyanate (diphenyl-methane di-isocyanate, (MDI) with a functionality of more than two) and a mixture of polyol (polyester with molecular weight of $800 \mathrm{~g} / \mathrm{mol}$ ) and chain extender (another polyol with a molecular weight of $400 \mathrm{~g} / \mathrm{mol}$ ). The catalysts of the types aluminosilicate and diamine were used for the reactions.

\section{Processing Methods and Tests}

To prepare the blend the homogenous mixture of PLA (80\%) and PBS (20\%) was extruded using a twin screw Brabender extruder machine (Brabender, Duisburg, Germany). The transformation temperature ranged from 180 to $200{ }^{\circ} \mathrm{C}$. Extruded films were obtained by pulling the product through a set of cooling rolls.

In order to prepare the samples, extruded films are cut by punch using a manual press. NF ISO 6239 standard [29] defines the test conditions and the shape of the samples. Two types of samples were obtained: parallel and perpendicular to the extrusion axis.

In the characterization methods the differential scanning calorimetry (DSC) measurements were carried out with the DSC Q10 V9.0 Build 275 (TA Instruments, Guyancourt, France). The samples of mass between 10 and $20 \mathrm{mg}$ were placed in hermetic aluminum capsules. The sample was heated first up to $200{ }^{\circ} \mathrm{C}$ with a temperature rate of $5{ }^{\circ} \mathrm{C} / \mathrm{min}$, in order to eliminate the effect of the thermal history of the material. It was cooled down to $-60{ }^{\circ} \mathrm{C}$ in order to be reheated up to $200{ }^{\circ} \mathrm{C}$ with the same temperature rate.

For the characterization of the viscoelastic behavior of PLA/PBS blends, the tests were carried out in tension using a dynamic mechanical analyzer (DMA) Q800 instrument, from the TA Company (Guyancourt, France). These tests were performed under the following condition: frequency $1 \mathrm{~Hz}$, temperature ranging from -80 to $120{ }^{\circ} \mathrm{C}$, temperature rate $2{ }^{\circ} \mathrm{C} / \mathrm{min}$, and dynamic force $0.1 \mathrm{~N}$. The sample had a rectangular shape with $25 \mathrm{~mm} \times 4 \mathrm{~mm} \times 2 \mathrm{~mm}$ dimensions. Multi-frequency tests were performed on virgin and $100 \%$ recovered polyurethane (PU) in order to use the Williams-Landel-Ferry (WLF) equation for the determination of free volume fraction and thermal expansion coefficient.

A shape memory cycle test consists of the following successive steps: tensile test, stress-relaxation test, fixing and recovery test. For reproducibility of the results, the shape memory tests were carried out on at least three samples, each time.

(i) Tensile test: Tensile tests were achieved with the Instron 5881 (Elancourt, France), loading cell of $1 \mathrm{kN}$, according to the standard NF ISO 6239 [29]. The strain rate is $5 \mathrm{~mm} / \mathrm{min}$. This machine is 
equipped with a temperature controlled thermo chamber for heating the samples and performing the tests at different temperatures.

(ii) Stress-Relaxation test: This test was performed at the end of the tensile test with the same machine. The strain was taken as constant (100\%, 200\% and 250\%) and the decrease of stress was measured versus time. This test was performed to eliminate the residual stress induced during the tensile test in the samples. The stress-relaxation tests were performed at 70,75 and $80{ }^{\circ} \mathrm{C}$.

(iii) Fixing: By cooling the sample with a ventilator at the end of the stress-relaxation test (or tensile test) the dimension of the sample, of the $100 \%, 200 \%$ and/or $250 \%$ strain was conserved in the sample.

(iv) Recovery test: The recovery tests are carried out in a thermal chamber at 70,75 and $80{ }^{\circ} \mathrm{C}$ and must follow the changes in size (length) of the samples as a function of time.

Because of the shape memory effect, the specimens regain a percentage of their initial shape.

In the multi-cycle method, successive shape memory tests were conducted on the same sample. After the first cycle (at the end of the recovery test) the sample was used for a second cycle in order to carry out the same tests successively; this means tensile, fixing (without relaxation test) and recovery test. The cycle was repeated several times.

\section{Experimental Results}

In terms of the thermal characteristics of the blend the results of DSC tests on PLA, PBS and PLA (80\%)/PBS (20\%) blend are presented in Table 1. It can be seen that the glass transition temperature $\left(T_{\mathrm{g}}\right)$ of PBS and PLA are respectively -38 and $58{ }^{\circ} \mathrm{C}$ and the melting point $\left(T_{\mathrm{m}}\right)$ of PLA and PBS are respectively 154 and $115^{\circ} \mathrm{C}$. These results were confirmed by the same tests on two other samples.

Table 1. Values of glass transition temperature $\left(T_{\mathrm{g}}\right)$ and melting point $\left(T_{\mathrm{m}}\right)$ of polylactic acid (PLA), polybutylene succinate (PBS) and the blend PLA/PBS.

\begin{tabular}{cccc}
\hline Polymer & $\boldsymbol{T}_{\mathbf{g}}\left({ }^{\circ} \mathbf{C}\right)$ & $\boldsymbol{T}_{\mathbf{m}}\left({ }^{\circ} \mathbf{C}\right)$ \\
\hline Pure polylactic acid (PLA) & 58 & 154 \\
\hline \multirow{2}{*}{ PLA 80\% + PBS 20\% } & PLA & 54 & 154 \\
\cline { 2 - 4 } & PBS & -38 & 115 \\
\hline Pure polybutylene succinate (PBS) & -38 & 115 \\
\hline
\end{tabular}

The DSC test on the blend shows two distinct $T_{\mathrm{g}}\left(-38\right.$ and $\left.54{ }^{\circ} \mathrm{C}\right)$ and two distinct $T_{\mathrm{m}}(115$ and $154^{\circ} \mathrm{C}$ ). These values are nearly the same as the $T_{\mathrm{g}}$ and $T_{\mathrm{m}}$ of PBS and PLA. This means that these polymers are not miscible in the blend. The same results were obtained by thermo-mechanical analysis (Figure 2). In this case, the loss modulus ( $\left.\mathrm{E}^{\prime \prime}\right)$ spectra also shows two distinct transition regions, at -30 and $51.5^{\circ} \mathrm{C}$, related respectively to the glass transitions of PBS and PLA. 
Figure 2. Storage $\left(E^{\prime}\right)$ and loss modulus $\left(E^{\prime \prime}\right)$ spectra of polylactic acid (PLA)/polybutylene succinate (PBS) blend.

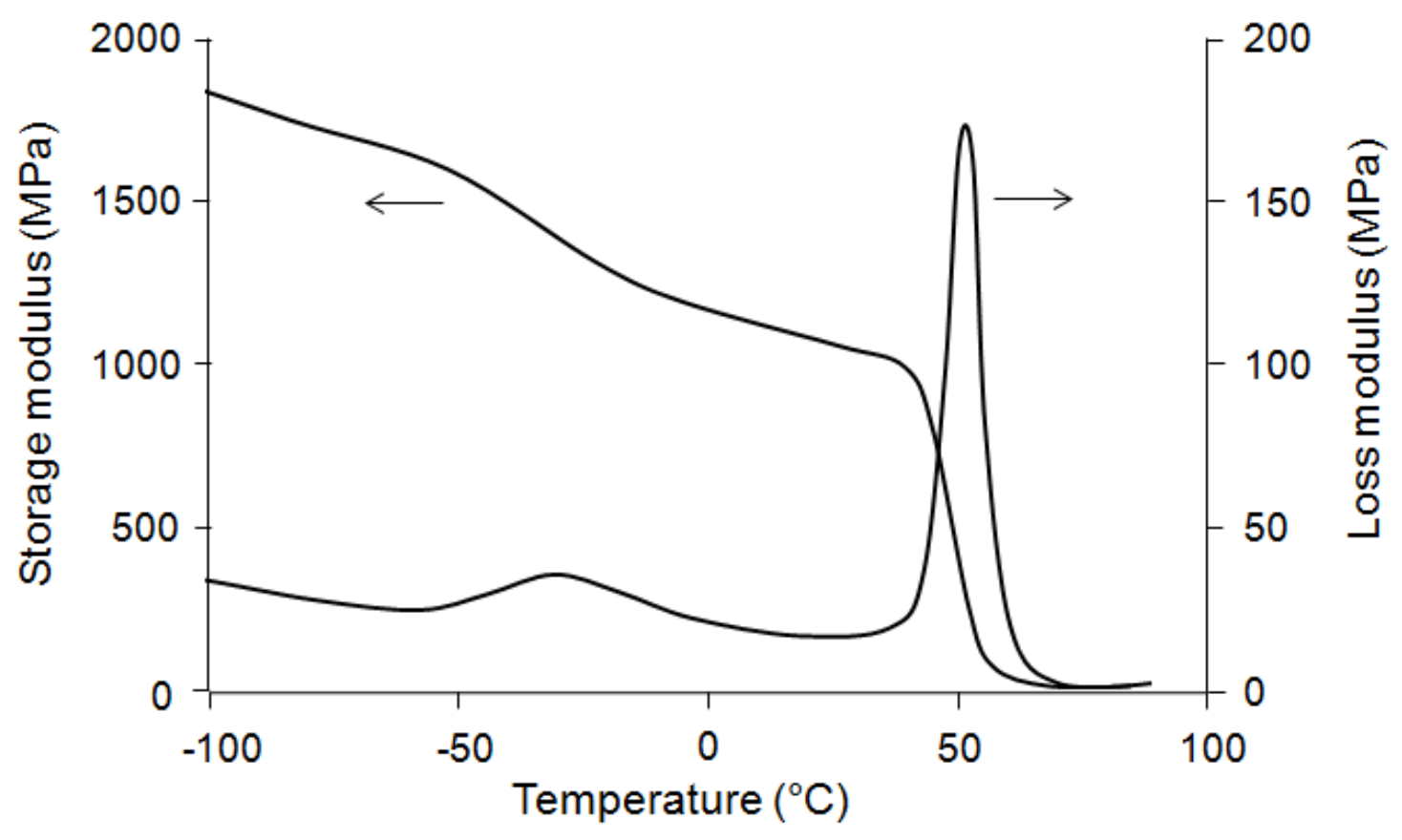

The immiscibility of these two polymers was observed previously by scanning electron microscopy (SEM) [28] with which the separation of two phases was shown clearly. However, it can be seen that by mixing $80 \%$ of PLA with $20 \%$ of PBS, the glass transition temperature of PLA in the blend decreases clearly from 58 to $54{ }^{\circ} \mathrm{C}$. This decrease of $T_{\mathrm{g}}$ value may be contributing to the plasticizing effect of PBS. The results of tensile tests on pure PLA and the PLA/PBS blends confirm this hypothesis (Table 2). The pure polymer PLA with a very low strain at break $(5.2 \%)$ is brittle at $24{ }^{\circ} \mathrm{C}$, while the PLA/PBS blend (parallel sample) with a strain at break more than $110 \%$ is ductile.

Table 2. Results of tensile tests at $24{ }^{\circ} \mathrm{C}$, on virgin PLA and blend of PLA/PBS (parallel samples).

\begin{tabular}{ccccccc}
\hline Polymer & & $\boldsymbol{E}(\mathbf{M P a})$ & $\boldsymbol{\sigma}_{\mathbf{y}}(\mathbf{M P a})$ & $\boldsymbol{\varepsilon}_{\mathbf{y}}(\%)$ & $\boldsymbol{\sigma}_{\mathbf{r}}(\mathbf{M P a})$ & $\boldsymbol{\sigma}_{\mathbf{r}}(\%)$ \\
\hline \multirow{2}{*}{ PLA } & Average & 1340 & - & - & 53 & 5.2 \\
& Standard deviation & 165 & - & - & 7.5 & 0.40 \\
\multirow{2}{*}{ PLA/PBS blend } & Average & 925 & 45 & 4.8 & 31.5 & 110 \\
& Standard deviation & 99 & 6.0 & 0.50 & 0.96 & 8.5 \\
\hline
\end{tabular}

In fact PBS has a melting point lower than PLA; during extrusion of the blend at a temperature higher than the melting point of PLA, PBS is at very low viscosity; it may partially penetrate between the molecular chains of PLA, like a plasticizer, even it is not miscible in PLA.

Figure 3 compares parallel and perpendicular samples. For parallel samples the value of strain at break is about $110 \%$ at room temperature; that means by blending $20 \%$ of PBS and $80 \%$ of PLA, the brittleness of PLA is improved and it becomes ductile. This is not the case for the perpendicular sample which always remains brittle. 
Figure 3. Stress-strain curves of PLA (80\%)/PBS $(20 \%)$ at $24{ }^{\circ} \mathrm{C}$ : perpendicular (1) and parallel (2) samples.
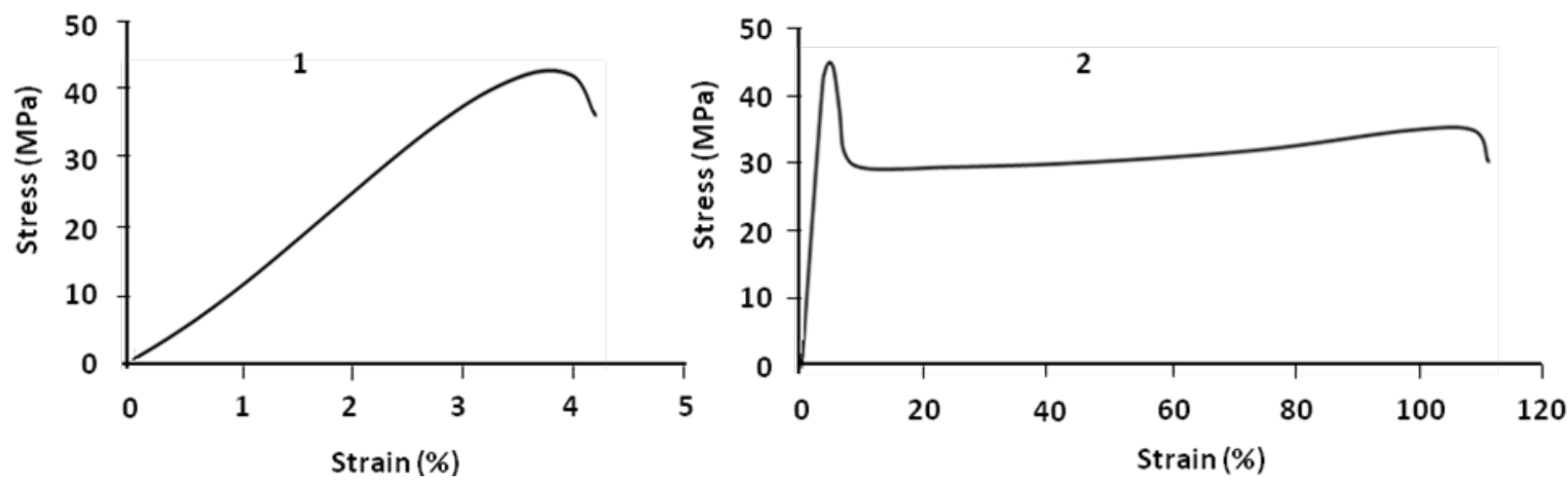

The difference between parallel and perpendicular samples may be explained as follows:

(i) During extrusion, the molecular chains of PLA and the discontinuous phase PBS became oriented in the direction of the flow (Figure 4). So, because of this orientation, the parallel sample $(E=925 \mathrm{MPa})$ is more rigid than the perpendicular sample $(E=855 \mathrm{MPa})$.

(ii) The standard deviation related to the results obtained from the tests on the parallel samples is more important than the perpendicular samples. In fact, the mechanical properties of the polymer in the center and at the edge of the film are not the same. The samples which are taken from these two zones have different properties.

Figure 4. Molten film of PLA/PBS blend during extrusion (1); perpendicular and parallel samples (2).

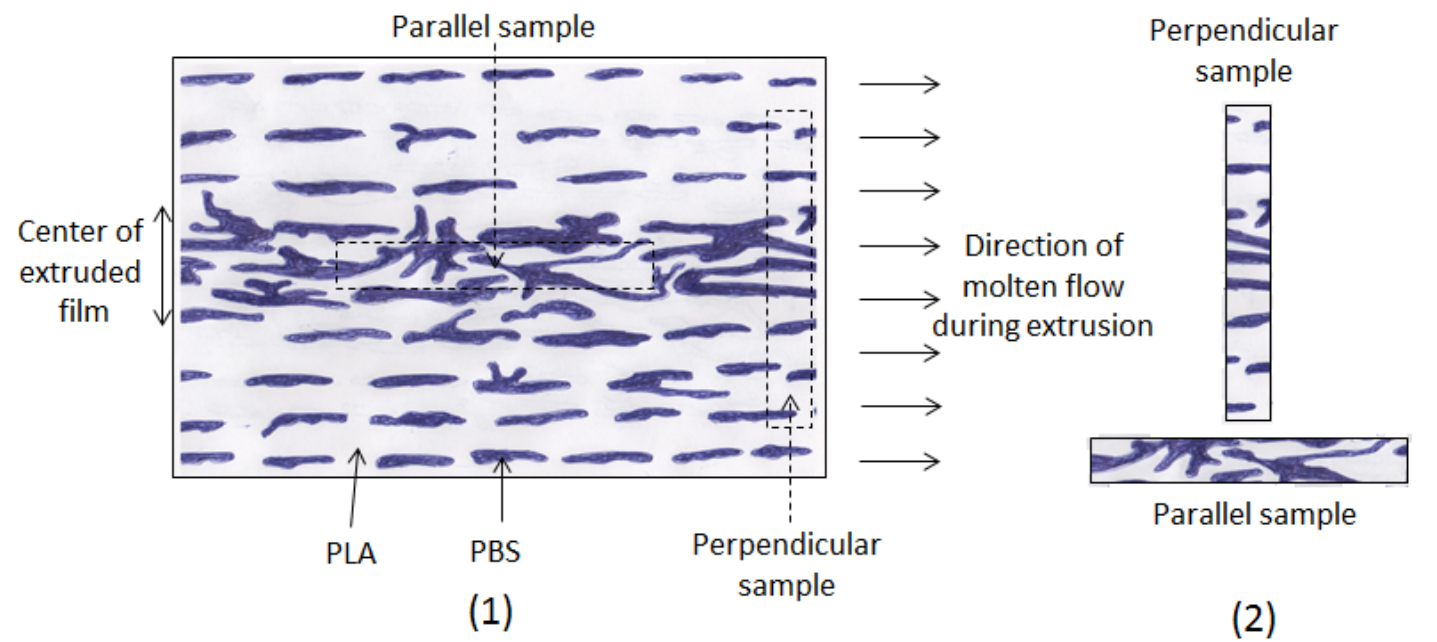

After obtaining these results, only parallel samples were used, taken from the center of the extruded film. This type of sample has high ductility $\left(\varepsilon_{\mathrm{r}}=110 \%\right.$ at room temperature), necessary for shape memory study.

Shape memory tests were carried out on the parallel extruded samples. In general, each shape memory cycle consists of the following successive tests: tensile, stress-relaxation, fixing and recovery. However, certain cycles were limited to tensile, fixing and recovery tests, without stress-relaxation tests. Tensile tests were performed on parallel samples at $70{ }^{\circ} \mathrm{C}$. The result is shown in Figure 5. 
Figure 5. Nominal stress-strain curves of parallel sample at $70{ }^{\circ} \mathrm{C}$.

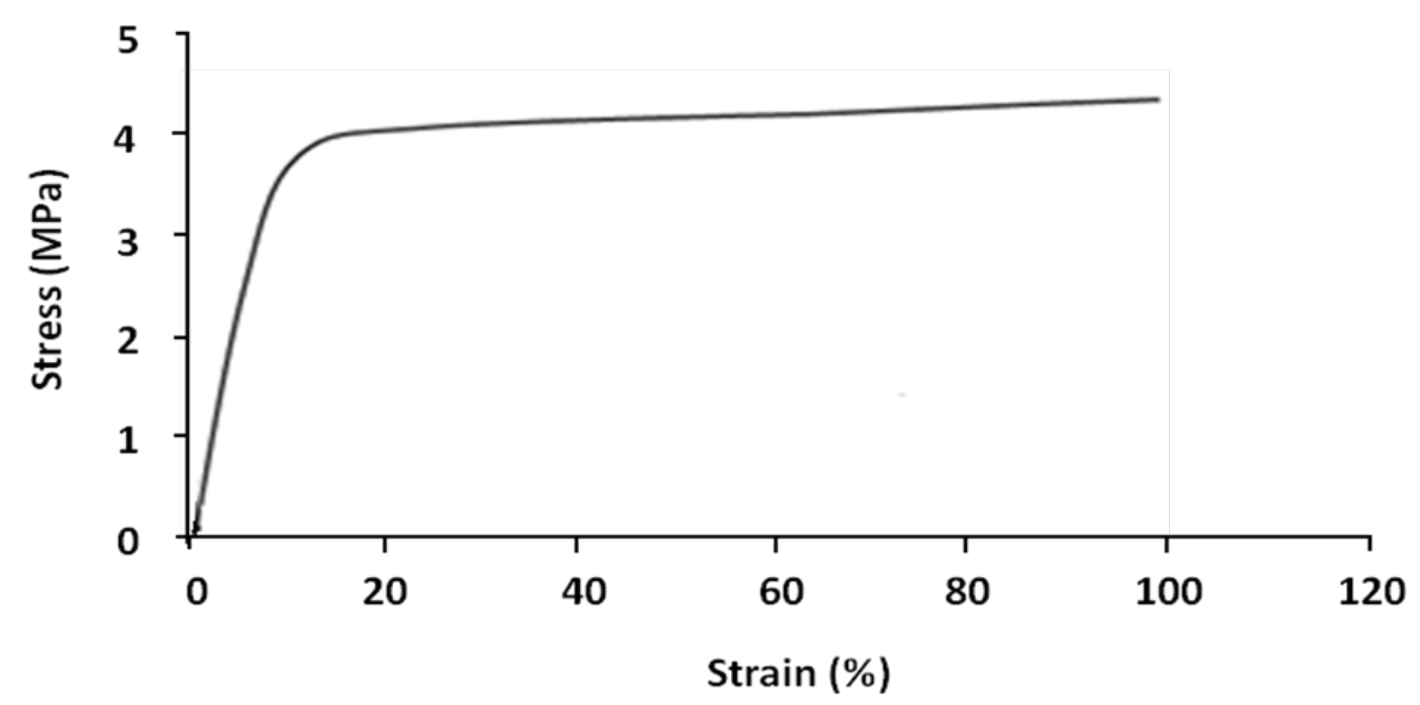

The sample has two different linear deformation zones; elastic zone ( $8 \%-10 \%$ strain) and plastic zone ( $>10 \%$ strain). At $100 \%$ strain the value of stress is about $4.3 \mathrm{MPa}$.

The stress-relaxation isothermal test was performed at the end of the tensile test with the same machine. The strain was taken constantly and the decrease of stress was measured versus time. This test was performed to eliminate the residual stress induced during the tensile test in the samples. The stress-relaxation tests were performed at 70,75 and $80{ }^{\circ} \mathrm{C}$ (Figure 6).

Figure 6. Relaxation tests at $70{ }^{\circ} \mathrm{C}(\mathbf{1}) ; 75^{\circ} \mathrm{C}(\mathbf{2})$ and $80{ }^{\circ} \mathrm{C} \mathrm{(3)}$.

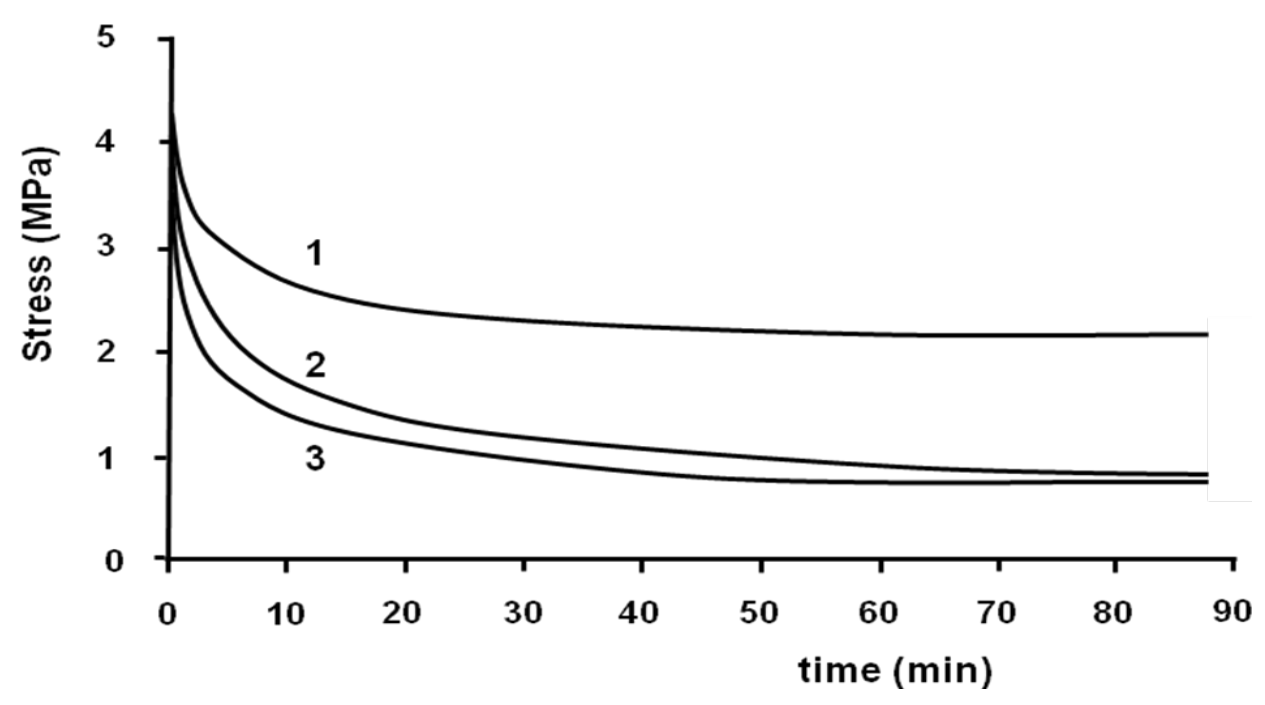

All stress-relaxation curves show two different regimes. At the beginning, the decrease of stress is relatively fast, and then it becomes slow. For example, at $70{ }^{\circ} \mathrm{C}$, the value of stress decreased from 4.3 to $2.3 \mathrm{MPa}$ after $20 \mathrm{~min}$. Then, it decreased to $2.1 \mathrm{MPa}$ after $90 \mathrm{~min}$. It can be seen that the relaxation does not lead the sample to zero stress.

The rate of relaxation and the value of stress at the end of the test depend on the temperature. The rate of decrease of stress is more important when the temperature is higher. The value of the 
stress at the end of the relaxation test at $70{ }^{\circ} \mathrm{C}$ is more important than $80{ }^{\circ} \mathrm{C}$. This value is the same at 75 and $80^{\circ} \mathrm{C}$.

Fixing can be performed after tensile tests or after stress-relaxation tests. During this step, the sample obtains a temporary shape. By cooling the sample with a ventilator, the maximum deformation $(100 \%, 200 \%$ and/or $250 \%)$ obtained at the end of tensile tests is conserved in the sample.

The recovery tests are carried out in a thermal chamber at 70 and $75{ }^{\circ} \mathrm{C}$ after fixing at $100 \%$ of deformation. The percentage of recovery was determined using Equation (1):

$$
R(\%)=\frac{L_{1}-L_{2}}{L_{1}-L_{0}} \times 100
$$

where, $L_{0}$ is the initial length of sample, $L_{1}$ represents the length of sample after tensile tests and $L_{2}$ is the length of sample after recovery test.

The results (Figure 7) show that the percentage of recovery in two cases $\left(70\right.$ and $75{ }^{\circ} \mathrm{C}$ ) is about $24 \%$. But the recovery rate at $75{ }^{\circ} \mathrm{C}$ is higher than the recovery rate at $70{ }^{\circ} \mathrm{C}$. For example after $5 \mathrm{~min}$, the sample regains only $7 \%$ of its initial shape when the temperature is $70{ }^{\circ} \mathrm{C}$, but this value is more than $21 \%$ (three times more) when the temperature is $75^{\circ} \mathrm{C}$.

The viscoelastic behavior of the blend is determined by comparing the thermodynamic behavior of the SMPs at different stages of the process. These results help to find the relationship between shape memory effect and the viscoelastic properties of the polymer. In fact, by increasing the temperature, the molecular motion becomes more and more important. The test on the stretched sample is especially interesting because, in the glass transition zone, the polymer tries to regain its initial shape.

Figure 7. Recovery tests at $70{ }^{\circ} \mathrm{C}(\bullet)$ and $75^{\circ} \mathrm{C}(\bullet)$.

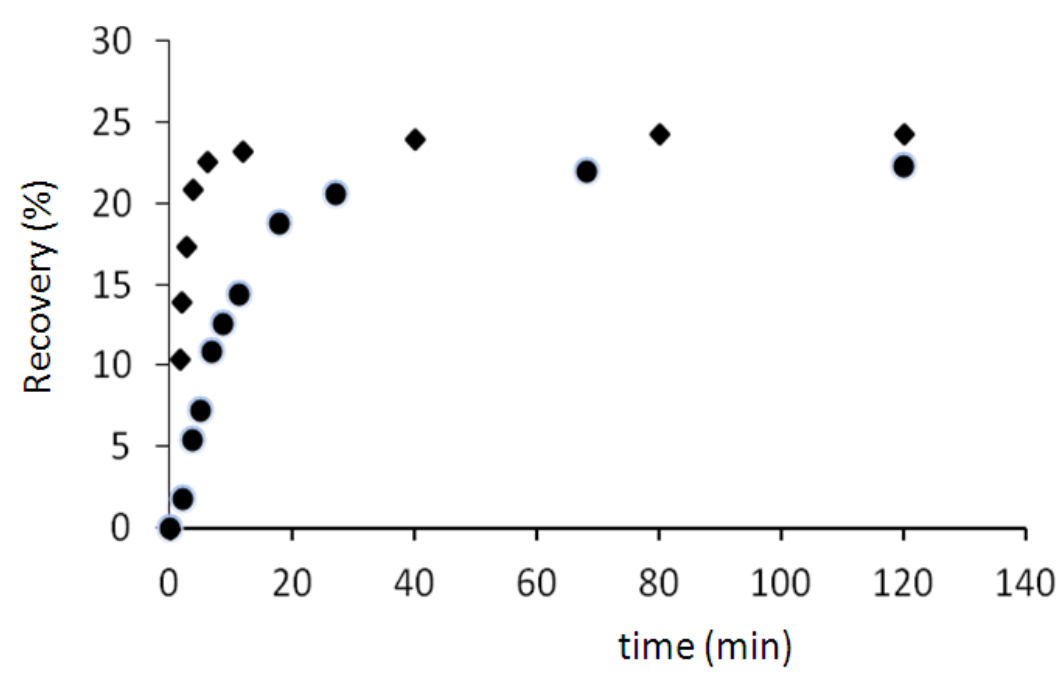

The results show that the stretching, relaxation test and fixing increase the value of the glass transition temperature. However, the comparison of the DMA spectrum of the samples before and after the recovery test reveals that the $T_{\mathrm{g}}$ of the blend decreases during the recovery test. In parallel samples, before the recovery test, the $T_{\mathrm{g}}$ is about $63.7^{\circ} \mathrm{C}$ while after the recovery test it shifts to $62.3{ }^{\circ} \mathrm{C}$. Indeed before the recovery test, the sample is stretched and its molecular mobility is decreased because of this stretching. 


\section{Analysis of a Multi-Cycle Shape Memory Test}

Multi-cycle shape memory tests were performed on the same sample according to the procedure, explained before. The results of the tensile tests (at $70^{\circ} \mathrm{C}$ ) of the different cycles are presented in Figure 8. In this figure, real stress is plotted versus real strain.

These tests were repeated at least with two other samples; the same results were obtained.

Figure 8. Real stress versus real strain (tensile tests) at the beginning of each cycle of shape memory tests at $70{ }^{\circ} \mathrm{C}$. (1) First cycle; (2) Second cycle; (3) Third cycle; and (4) Fourth cycle.

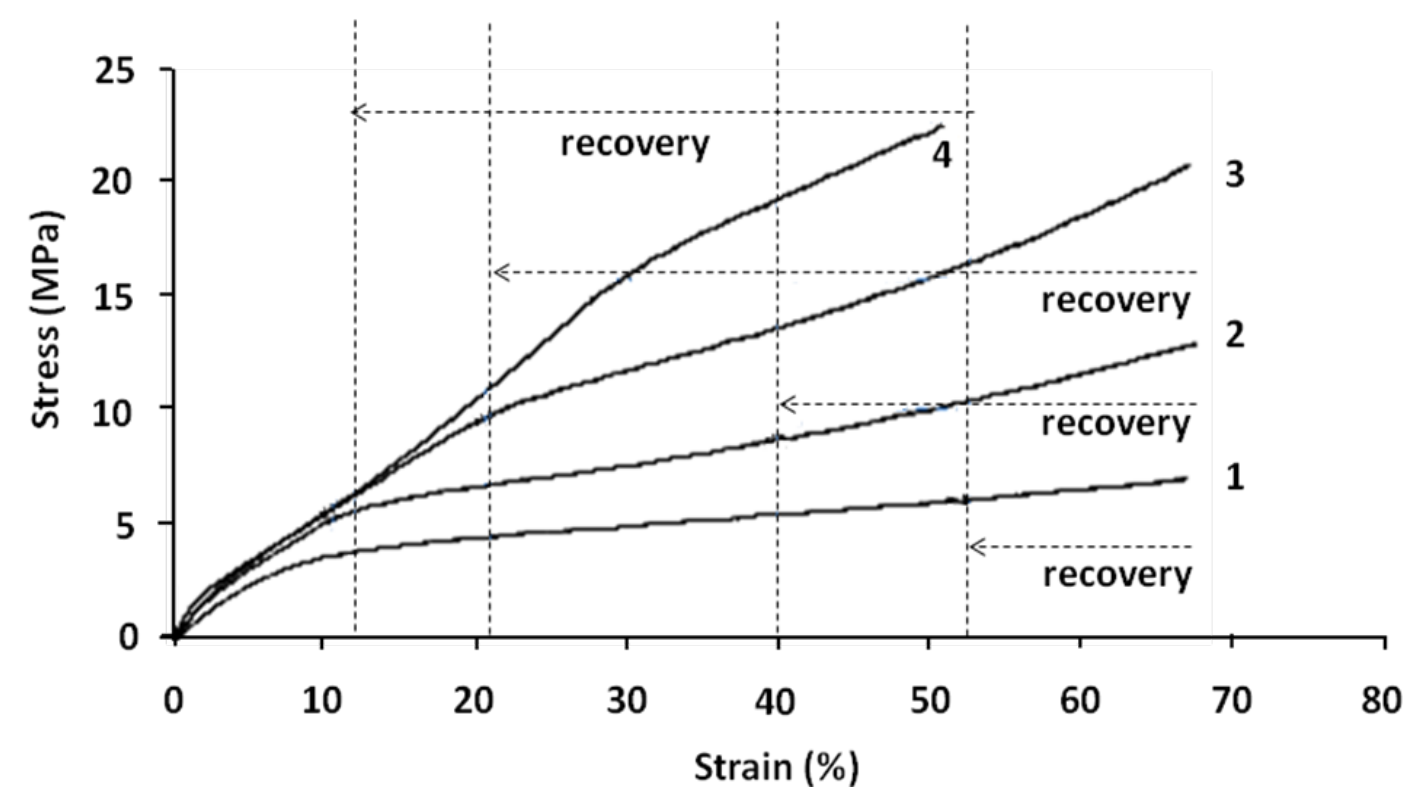

The different cycles may be analyzed as follows:

(1) Cycle 1 can be divided into two zones with:

a. Elastic stage up to $6 \%-8 \%$ of deformation and with a Young's modulus of $50 \mathrm{MPa}$;

b. Plastic linear stage up to $69 \%$ of real strain. After recovery test, the sample regains $24 \%$ of deformation $(6 \%-8 \%$ of elastic part and $16 \%-18 \%$ of plastic part).

(2) Cycle 2 begins at the end of the first cycle and after the recovery test. This cycle is obviously divided into three linear stages.

a. First stage up to $3 \%-4 \%$ of deformation and with a modulus of $110 \mathrm{MPa}$;

b. Second stage up to $12 \%$ of real strain and with a modulus of $41 \mathrm{MPa}$. The stress-strain curve at this stage is relatively linear;

c. Third stage with a modulus of $11 \mathrm{MPa}$. In this stage, the stress-strain curve remains first linear up to $30 \%$ of deformation; then its slope increases.

(3) Cycle 3 begins at the end of the second cycle and after recovery test. This cycle is also divided into three linear stages.

a. First stage up to $3 \%-4 \%$ of deformation and with a modulus of $115 \mathrm{MPa}$;

b. Second stage up to $20 \%$ of real strain and with a modulus of $42 \mathrm{MPa}$. The stress-strain curve at this stage is relatively linear; 
c. Third stage with a modulus of $20 \mathrm{MPa}$. In this stage, the stress-strain curve is relatively linear up to $45 \%$ of deformation. Then its slope increases because of the molecular orientation.

(4) Cycle 4 begins at the end of the third cycle and after recovery test. As in previous cycles, it is separated into three different stages.

a. First stage up to $3 \%-4 \%$ of deformation and with a modulus of $130 \mathrm{MPa}$;

b. Second stage up to $30 \%$ of deformation and with a modulus of $44 \mathrm{MPa}$. In this stage, the stress-strain curve is not linear; the increase of its slope may be related to the molecular orientation;

c. Third stage up to $50 \%$ of real strain and with a modulus of $37 \mathrm{MPa}$. In this stage, the stress-strain curve is relatively linear.

These results can be summarized by the following comments:

(1) It can be seen that during the first cycle, the stress-strain curve is a classical one. From the second cycle, the obtained tensile curves show three stages. Stage 1 seems to correspond to an elastic behavior. Stage 2 is an intermediate behavior stage. Stage 3 follows Stage 2 until the end of the test;

(2) The slope measured during Stage 1, assumed to be a Young's modulus, $E_{1}$ increases with the number of cycles, from 50 to $130 \mathrm{MPa}$ (Figure 9 and Table 3). This increase in the stiffness of the blend may be related to the reinforcement of the homogenous matrix, PLA phase (hard segment). The orientation of molecular chains in the PLA structure may be presumed as the cause of this reinforcement. However the change of $E_{1}$ between first and second cycles is more important (from 50 to $110 \mathrm{MPa}$ ). From the second cycle, $E_{1}$ changes less and the variation of its value is not very significant.

Figure 9. Relationship between tensile modulus and recovery percentage related to the first zone $\left(E_{1}\right)$ and the second and third zones $\left(E_{2}\right.$ and $\left.E_{3}\right)$ of stress-strain curves (at $\left.70{ }^{\circ} \mathrm{C}\right)$ of different successive cycles.

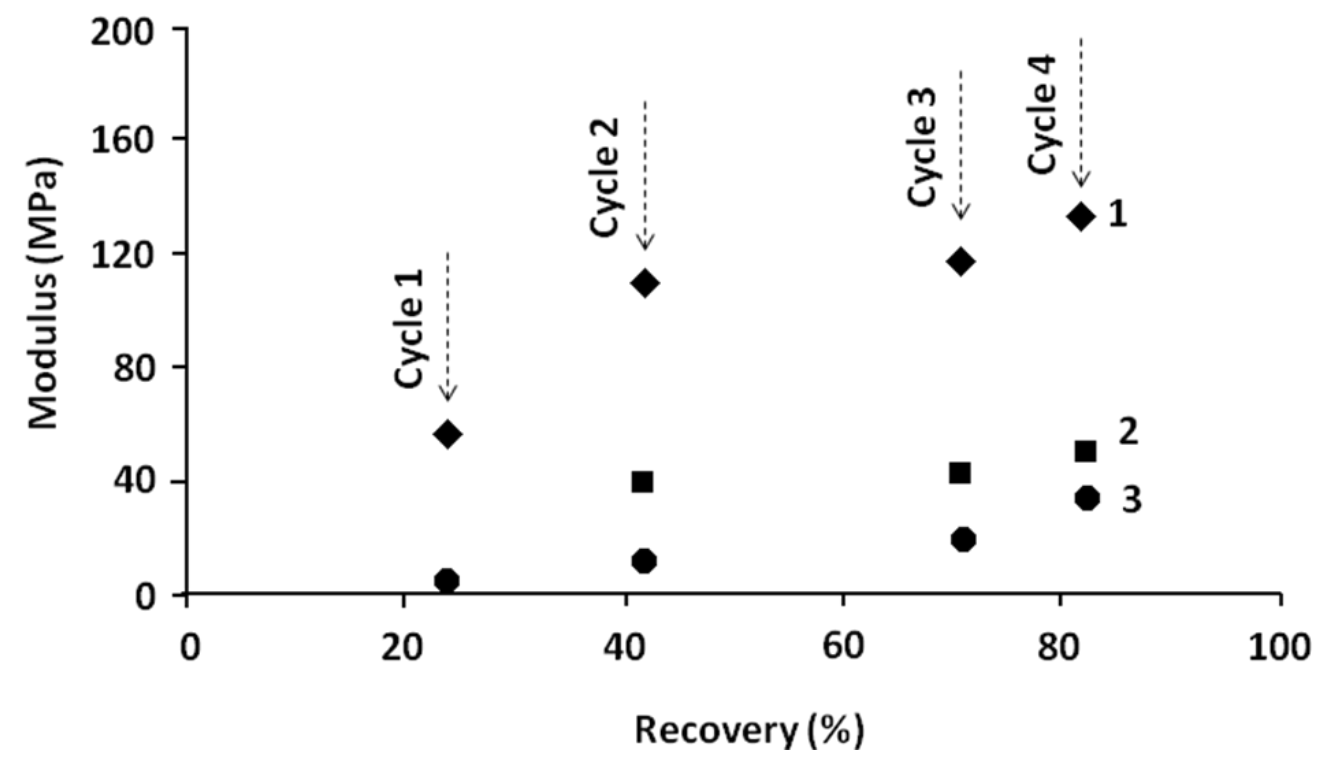


Table 3. Relationship between percentage of recovery and modulus related to the different stages of different cycles of multi-cycle tests.

\begin{tabular}{ccccccc}
\hline Cycle No. & Stage & Residual stress (MPa) & Recovery $(\%)$ & $\boldsymbol{E}_{\mathbf{1}}(\mathbf{M P a})$ & $\boldsymbol{E}_{\mathbf{2}}(\mathbf{M P a})$ & $\boldsymbol{E}_{\mathbf{3}}(\mathbf{M P a})$ \\
\hline 0 & Initial & 0 & - & - & - & - \\
\multirow{2}{*}{1} & before recovery & 7.2 & & & & \\
& after recovery & 6.5 & $24 \%$ & 50 & - & 5 \\
2 & before recovery & 13.1 & & & & \\
& after recovery & 9.5 & $42 \%$ & 110 & 41 & 11 \\
3 & before recovery & 21 & & & & \\
& after recovery & 11 & $71 \%$ & 115 & 42 & 20 \\
4 & before recovery & 22.9 & & & & \\
& after recovery & 6.5 & $82 \%$ & 130 & 44 & 37 \\
\hline
\end{tabular}

(3) Regarding the formation and development of Stage 2, several remarks on the constitutive tensile curve should be made:

(a) The slope of the curves related to this stage remains in the same order of magnitude (41-44 MPa) and its value is nearly the same as that of the original stiffness of the material in cycle $1(50 \mathrm{MPa})$;

(b) The extent of this stage increases significantly with the number of cycles;

(c) The slope of Stage 3 increases also with the number of cycles. In this stage, the last part of the curves presents a transition zone of kinetic change. After this zone, the material becomes stiff. This is classically attributed to the orientation of the macromolecular chains. One should draw attention to the fact that the level of stress measured at this point is always of the same order of magnitude as the level of stress reached at the transition ("yield point") between Stages 2 and 3 at the next cycle. For example, the transition zone of curve 1 (around $6 \mathrm{MPa}$ ) corresponds to the level of the stress observed at the "yield point" (between Stages 1 to 2) of the curve 2.

For a first approach, the Stage 2 of the curve 2 may be considered also as the expression of an elastic behavior. Indeed, in order to understand the origin of the appearance and development of Stage 2, we propose here an original phenomenological interpretation of the consecutive tensile curves. Let us first take a classical case. When the polymer is under plastic deformation (and more generally "anelastic deformation"), we can assume that the total strain $\left(\varepsilon_{\text {tot }}\right)$ can be divided in two parts, elastic $\left(\varepsilon_{\mathrm{e}}\right)$ and plastic $\left(\varepsilon_{\mathrm{p}}\right)$ deformations:

$$
\varepsilon_{\text {tot }}=\varepsilon_{\mathrm{e}}+\varepsilon_{\mathrm{p}}
$$

In the case of linear elasticity:

$$
\varepsilon_{\mathrm{e}}=\frac{\sigma}{E}
$$

At the end of the first cycle, during fixing, the temperature decreases under the glass transition zone and the sample passes from a rubbery state $\left(70^{\circ} \mathrm{C}\right)$ to a glassy state (room temperature) leading to an increase of the Young's modulus. Thus the elastic part decreases (Equation (3)) and tends to zero, 
leading to an increase of plastic (anelastic) strain which tends towards the imposed total strain (Equation (2)). So the yield stress on the curve related to cycle 2 corresponds to the stress at the end of fixing during cycle 1 . On the other hand, from the phenomenological point of view, fixing leads to a hardening of the polymer.

When performing recovery, the specimen is submitted to a driving force. Figure 10 shows the elevation of temperature up to the glass transition which leads to a decrease of the stiffness simultaneously, due to decrease in the plastic strain (equilibrium between plastic and elastic strain, see Equation (2)), where the elastic part of the strain is released.

Figure 10. Variation of modulus versus temperature (fixing and recovery).

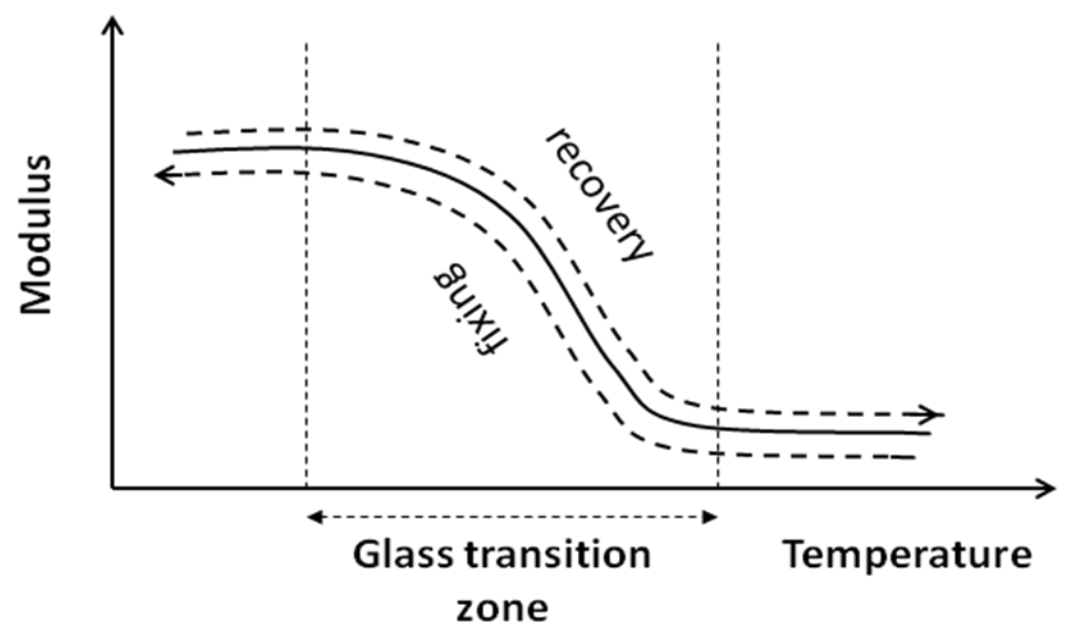

Moreover the extent of Stage 2 increases significantly with the number of the cycle. This phenomenon may be understood by the hardening effect due to the fixing as it has been explained by the fact that the level of stress at this point is always of the same order of magnitude as the "yield point" of the previous cycle. This expression of a second elastic phase can be explained by different physical phenomena as, for example, the local effect due to the multi-phased configuration. Indeed, the localization of the deformation around the heterogeneity coupled with chain orientation can produce this kind of effect. This will be discussed in a further paper through the results of a micromechanical model using the concept of a coated heterogeneity.

(4) Additionally, the presence of a transition zone on Stage 2 for curve 4 (cycle 4) can be noticed. It seems after several cycles the orientation of the chain has been greatly facilitated and can be activated sooner even during cycle 2 .

\section{Shape Memory Effect}

Some new concepts of shape memory effect are discussed by looking at the origin of the recovery and driving force. For example, partial shape memory effect, relationship between the shape and properties of SMP, and shape memory in micro-scale domains. 


\subsection{Origin of the Recovery and Driving Force}

Because of the temperature increase during the recovery test, the stiffness of the polymer decreases leading to the decrease of the elastic (or viscoelastic) part of the strain. Consequently, the partition of the strain of Equation (1) leads to the decrease of the plastic strain. The release of the elastic part of the strain contributes partially to the recovery.

The driving force responsible for the shape memory effect is in fact the residual stress introduced in the sample during the tensile test.

In the case of polymers without shape memory, this deformation in the plastic zone is irreversible. The sample will recover only the elastic portion of deformation when it is released in the plastic zone. In this case if the test temperature is below the $T_{\beta}$ and the polymer is in its glassy state, due to a low mobility, the elastic deformation will be small and the sample remains relatively far from its original form. However, if the test temperature is above the $T_{\beta}$ and especially when the polymer is in a rubbery state, with a high molecular mobility, the elastic deformation may be very important and when the sample is released at the end of the tensile test, it can regain an important part of its original shape.

In the case of shape memory polymers, after the tensile test is at $100 \%$ of deformation, a stress will be introduced in the sample. By the relaxation test (Figure 11) after the tensile test, two portions of residual stress can be distinguished.

Figure 11. Schematic relaxation curve.

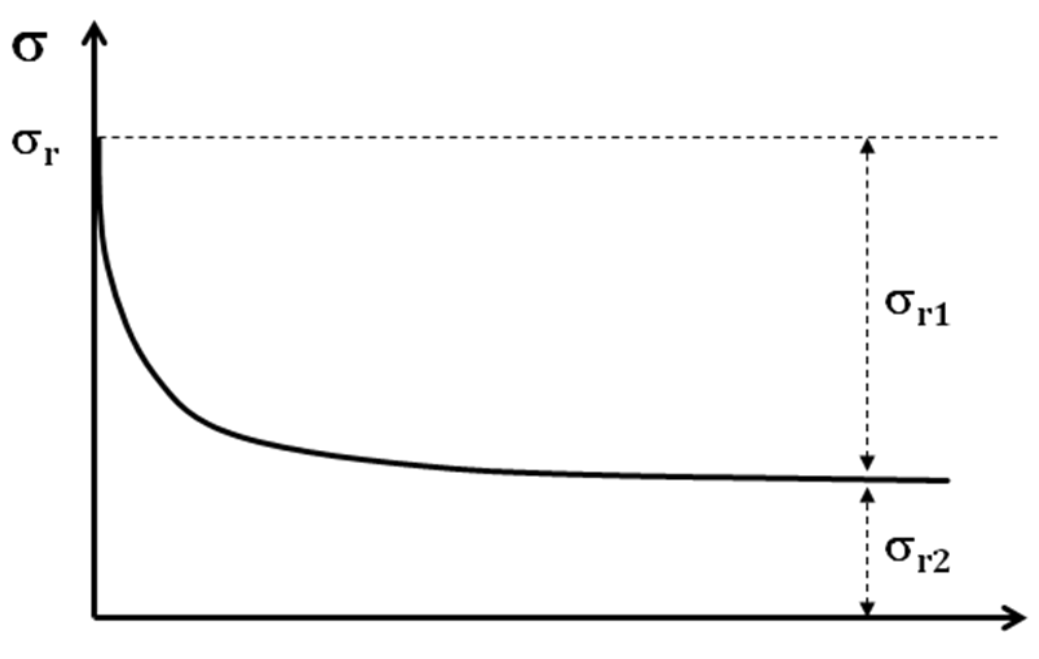

The first portion, $\sigma_{\mathrm{r} 1}$, will be eliminated at the end of the relaxation test; but the second portion of this residual stress $\sigma_{\mathrm{r} 2}$, remains in the structure of the sample. This stress is the origin of shape memory effect. If the shape memory cycle test is performed without the relaxation test, as the value of residual stress is higher, the SMP regains its initial form faster. In any case the SMP regains its initial shape with or without the relaxation test. The residual stress then can be considered as the driving force of a SMP for regaining the initial shape.

In order to show the role of this driving force, the residual stress is recapitulated and plotted versus the percentage of recovery respectively in Table 4 and Figure 12. These results were obtained from the shape memory tests with and without stress-relaxation experiments. 
Table 4. Relationship between residual stress and percentage of recovery.

\begin{tabular}{cccc}
\hline No. & Residual real stress (MPa) & Temperature of recovery tests $\left({ }^{\circ} \mathbf{C}\right)$ & Recovery $(\%)$ \\
\hline 1 & 1.22 & 80 & 4.72 \\
2 & 1.25 & 80 & 5.17 \\
3 & 3.81 & 80 & 17.14 \\
4 & 3.83 & 80 & 17.20 \\
5 & 5.37 & 80 & 18.20 \\
6 & 5.51 & 80 & 19.00 \\
7 & 7.10 & 70 & 19.12 \\
8 & 7.41 & 70 & 19.21 \\
9 & 7.73 & 70 & 20.51 \\
10 & 8.22 & 75 & 20.86 \\
11 & 8.47 & 70 & 23.50 \\
12 & 8.73 & 80 & 22.30 \\
13 & 7.78 & 70 & 22.35 \\
14 & 9.39 & 70 & 23.00 \\
15 & 11.02 & 75 & 24.00 \\
16 & 11.69 & 75 & 24.34 \\
17 & 29.32 & 70 & 42.00 \\
18 & 56.61 & 70 & 70.90 \\
19 & 90.17 & 70 & 81.80 \\
\hline
\end{tabular}

Figure 12. Percentage of recovery versus residual real stress.

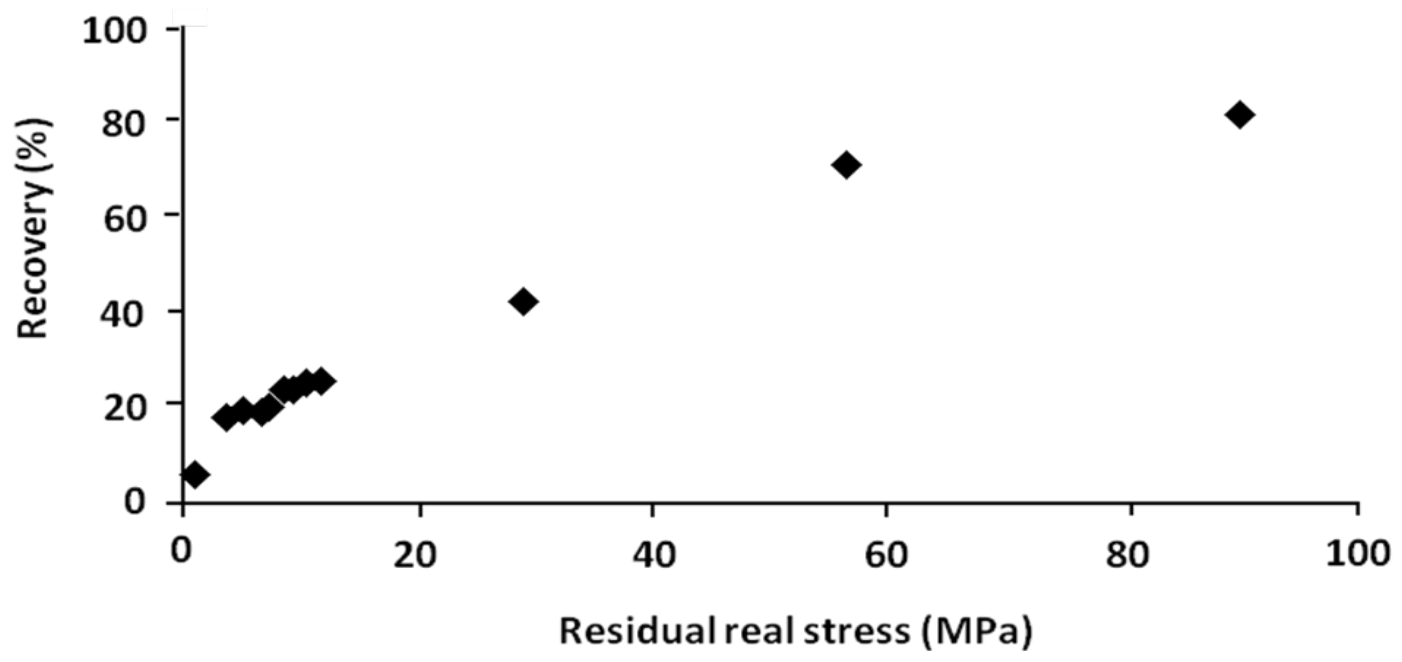

\subsection{Partial Shape Memory Effect}

As we have seen before, the blend under study (PLA (80\%)/PBS (20\%)) is not a $100 \%$ shape memory polymer. At the beginning the blend has a partial shape memory effect with a recovery rate of $24 \%$. Figure 13 shows that after each cycle, the blend has been modified and transformed to a new blend with SME. This effect increases after each cycle; $42 \%$ after the second cycle, $71 \%$ after the third cycle and reaches $82 \%$ after the fourth cycle. The evolution of the shape memory capacity of a polymer which is not originally a SMP, can reinforce the following ideas: As it was explained before, logically a polymer with partial shape memory effect may be transformed into a 100\% SMP. However, this idea 
must be confirmed by experiments. In any case the improvement of shape memory properties of a PSMP is very attractive for industry.

Figure 13. Evolution of shape memory effect (SME) of PLA/PBS by succesive shape memory tests.

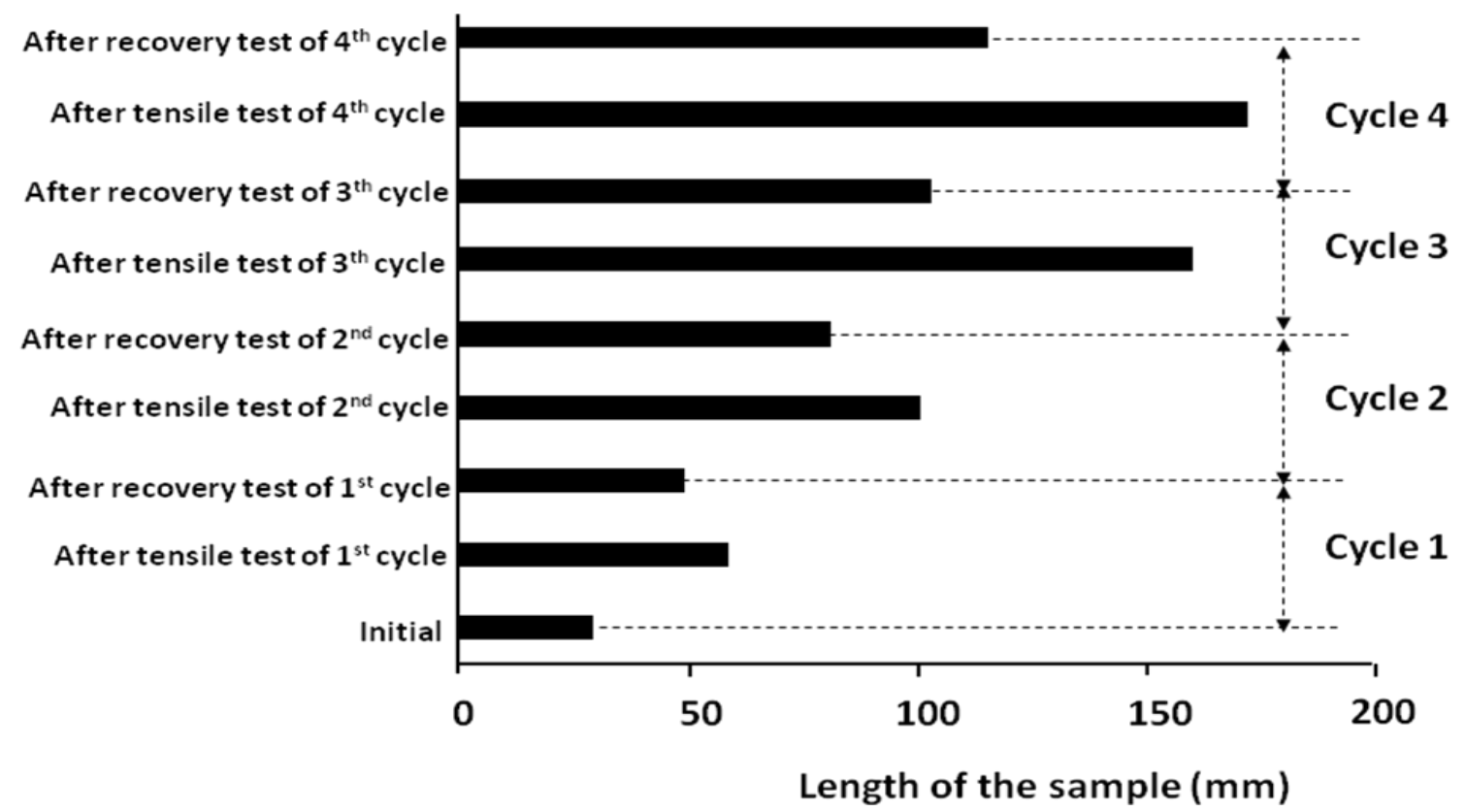

\subsection{Shape Memory in Micro-Scale Domains}

In the previous paper [26], it was shown by dynamic mechanical analyzer (DMA) tests on polyurethane (with shape memory effect) that after recovery test and even after regaining $100 \%$ of the initial shape, the sample does not have the same properties. It was seen that, $\mathrm{G}^{\prime}$ (storage modulus) and $\mathrm{G}^{\prime \prime}$ (loss modulus) of recovered and virgin samples were different with different alpha transition temperatures. These results were followed by the successive cycles tests, performed on the same sample. The results indicated that the Young's modulus of the virgin sample of SMP and the same sample after recovery test was not the same.

Another physical property which is related to the microstructure is free volume, shown by free volume fraction $f_{\mathrm{g}}$. This parameter may be determined by the results of multi-frequency DMA tests on polyurethane (Figure 14), using the Williams-Landel-Ferry (WLF) equation:

$$
\log \frac{F}{F_{\mathrm{r}}}=\frac{-C_{1}\left(T_{\alpha}-T_{\alpha \mathrm{r}}\right)}{C_{2}+\left(T_{\alpha}-T_{\alpha \mathrm{r}}\right)}
$$

where $F=$ frequency, $T_{\alpha}=\alpha$ transition temperature, $F_{\mathrm{r}}=$ reference frequency, $T_{\mathrm{\alpha r}}=$ reference temperature, $C_{1}=B / 2.303 f_{\mathrm{g}}, C_{2}=f_{\mathrm{g}} / \Delta \alpha, B \approx 1, \Delta \alpha=$ thermal expansion coefficient and $f_{\mathrm{g}}=$ free volume fraction.

In order to verify the validity of this equation, the linear regression method was used and $1 /\left(\log F / F_{\mathrm{r}}\right)$ was plotted versus $1 /\left(T_{\alpha}-T_{\alpha \mathrm{r}}\right)$. If this plot is linear having $S=C_{2} / C_{1}$ as slope then the validity of the WLF equation is verified and $f_{\mathrm{g}}$ may be determined by the following equation: 


$$
f_{g}=\sqrt{\frac{B \cdot \Delta \alpha \cdot S}{2.303}}
$$

Using this method, we performed multi-frequency 3 point bending DMA tests on the PU. The test conditions are as follows: frequency range $0.1-100 \mathrm{~Hz}$, temperature range $25-80{ }^{\circ} \mathrm{C}$. The results are shown in Table 5. These results show clearly that $T_{\mathrm{g}}, \Delta \alpha$ and $f_{\mathrm{g}}$ of virgin and recovered (100\%) samples are not the same. That means that the PU under study shows SME but not memory effect for certain properties.

Figure 14. Multi-frequency 3 point bending dynamic mechanical analyzer (DMA) test on virgin polyurethane (PU): (1) $0.1 \mathrm{~Hz}$; (2) $1 \mathrm{~Hz}$; (3) $10 \mathrm{~Hz}$; and (4) $100 \mathrm{~Hz}$.

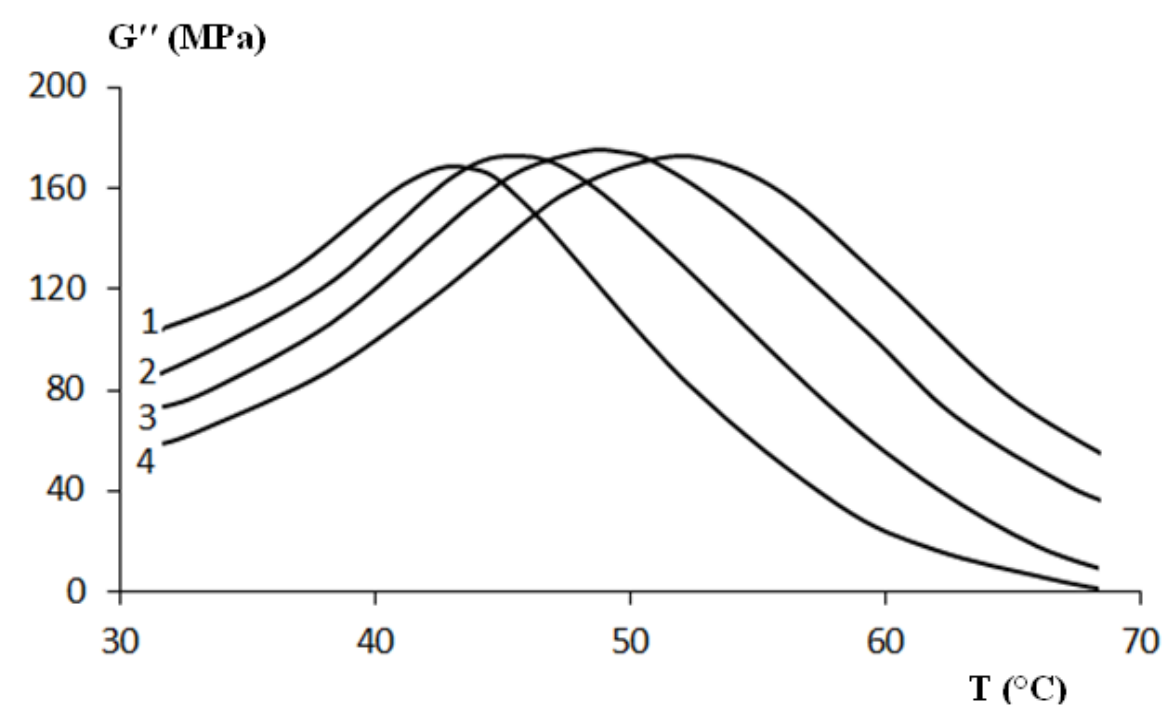

Table 5. The values of constants of WLF obtained by multi-frequency 3 point bending dynamic mechanical analyzer (DMA) test on polyurethane (PU).

\begin{tabular}{ccccccc}
\hline PU & $\boldsymbol{T}_{\mathrm{g}}(\mathbf{K})$ & $\boldsymbol{C}_{\mathbf{1}}$ & $\boldsymbol{C}_{\mathbf{2}}(\mathbf{K})$ & $\boldsymbol{S}(\mathbf{K})$ & $\Delta \boldsymbol{\alpha}\left(\mathbf{K}^{-\mathbf{1}}\right)$ & $\boldsymbol{f}_{\mathrm{g}}$ \\
\hline Virgin & 318.5 & 0.0647 & 15.5 & 3.8 & 5.5 & 0.0301 \\
Recovered (100\%) & 314 & 0.0570 & 17.2 & 4.7 & 5.2 & 0.0326 \\
\hline
\end{tabular}

After recovery tests and regaining initial shape, it is possible that the sample does not regain some of its initial properties because of microstructure irreversible changes. These microstructure changes may induce the micro-change of volume which cannot be regained after the recovery test. In a study of shape memory effect, generally, the authors measure the macro-change of volume. They do not give enough attention to the micro-change of volume. In fact on the macroscopic scale, the measurement of micro-changes is practically impossible. 
The difference has been explained by the presence of two types of properties:

- The properties like density or Poisson's ratio which are related directly to the macro-structure (shape) of the sample. These properties may be regained after recovery tests.

- The properties like modulus or glass transition temperature which is related to the micro-structure (in molecular or macromolecular scale). During shape memory test, the mechanism of their evolution is not the same as the mechanism of the shape memory effect. So these properties may not be regained totally after the recovery test.

\section{Conclusions}

This study proposes certain new concepts for shape memory polymers. For properties memory effect (PME) from the results of DSC tests, tensile tests, DMA test, and by using the WLF equation on virgin and 100\% recovered polyurethane, we determined the value of: modulus, strength, glass transition temperature, heat coefficient expansion and free volume fraction. The results show that they do not have the same properties indicating that shape memory effect and properties memory effect may have two different mechanisms.

For the partial shape memory effect (PSME), the multi-cycle shape memory tests show that blend PLA ( $80 \%) /$ PBS $(20 \%)$, regains only $24 \%$ of the initial shape at the end of the first cycle, indicating that certain polymers have a partial shape memory effect. This test also showed the shape capacity of polymer increases by the number of cycles. The same polymer after the second, third, and fourth cycles regains respectively, $42 \%, 71 \%$ and $82 \%$ of its initial shape. This new concept of shape memory effect is of very important value. We can in a legitimate way suppose that a polymer without shape memory effect can be transformed into a shape memory polymer.

Finally, for the shape memory effect in micro, as certain properties of polymers can be affected by the micro change of the shape (elasticity, free volume, etc.), it is very important to study the shape memory effect on the micro-scale. In fact, the shape memory effect has always been studied macroscopically. This study may not in itself be sufficient to fully explain the relationship between shape memory effect and properties memory effect.

\section{Acknowledgments}

The polyurethane (PU) samples used for this study have been supplied by RAIGI (Rouvray-SaintDenis, France). The authors thank the company for its precious help.

\section{Conflicts of Interest}

The authors declare no conflict of interest.

\section{References}

1. Hu, J.; Zhu, Y.; Huang, H.; Lu, J. Recent advances in shape-memory polymers: Structure, mechanism, functionality, modeling and applications. Prog. Polym. Sci. 2012, 37, 1720-1763.

2. Monkman, G.J. Advances in shape memory polymer actuation. Mechatronics 2000, 10, 489-498.

3. Behl, M.; Lendlein, A. Actively moving polymers. Soft Matter 2007, 3, 58-67. 
4. Behl, M.; Zotzmann, J.; Lendlein, A. Shape-memory polymers and shape-changing polymers. In Shape-Memory Polymers; Lendlein, A., Ed.; Springer: Berlin/Heidelberg, Germany, 2010; pp. 1-40.

5. Baer, G.; Wilson, T.S.; Matthews, D.L.; Maitland, D.J. Shape-memory behavior of thermally stimulated polyurethane for medical applications. Appl. Polym. Sci. 2007, 103, 3882-3892.

6. Liu, C.; Qin, H.; Mather, P.T. Review of progress in shape-memory polymers. J. Mater. Chem. 2007, 17, 1543-1558.

7. Wei, Z.G.; Sandstroröm, R.; Miyazaki, S. Shape-memory materials and hybrid composites for smart systems - Part I: Shape-memory materials. J. Mater. Sci. 1998, 33, 3743-3762.

8. Ratna, D.; Karger-Kocsis, J. Recent advances in shape memory polymers and composites: A review. J. Mater. Sci. 2008, 43, 254-269.

9. Golbang, A.; Kokabi, M. Temporary shape development in shape memory nanocomposites using magnetic force. Eur. Polym. J. 2011, 47, 1709-1719.

10. Lendlein, A.; Behl, M. Shape-memory polymers for biomedical applications. Adv. Sci. Technol. 2009, 54, 96-102.

11. El Feninat, F.; Laroche, G.; Fiset, M.; Mantovani, D. Shape memory materials for biomedical applications. Adv. Eng. Mater. 2002, 4, 91-104.

12. Gall, K.; Yakacki, C.M.; Liu, Y.; Shandas, R.; Willett, N.; Anseth, K.S. Thermomechanics of the shape memory effect in polymers for biomedical applications. J. Biomed. Mater. Res. A 2005, 73A, 339-348.

13. Nguyen, T.D.; Qi, H.J.; Castro, F.; Long, K.N. A thermoviscoelastic model for amorphous shape memory polymers: Incorporating structural and stress relaxation. J. Mech. Phys. Solids 2008, 56, 2792-2814.

14. Li, G.; Xu, W. Thermomechanical behavior of thermoset shape memory polymer programmed by cold-compression: Testing and constitutive modeling. J. Mech. Phys. Solids 2011, 59, 1231-1235.

15. Heuchel, M.; Cui, J.; Kratz, K.; Kosmella, H.; Lendlein, A. Relaxation based modeling of tunable shape recovery kinetics observed under isothermal conditions for amorphous shape-memory polymers. Polymer 2010, 51, 6212-6218.

16. Chen, X.; Nguyen, T.D. Influence of thermoviscoelastic properties and loading conditions on the recovery performance of shape memory polymers. Mech. Mater. 2011, 43, 127-138.

17. Ferry, J.D. Introduction to polymer viscoelasticity. In Journal of Polymer Science: Polymer Letters Edition; Aklonis, J.J., MacKnight, W.J., Shen, M., Eds.; Wiley-Interscience: New York, NY, USA, 1973; Volume 11, pp. 293-294.

18. Srivastava, V.; Chester, S.A.; Anand, L. Thermally actuated shape-memory polymers: Experiments, theory, and numerical simulations. J. Mech. Phys. Solids 2010, 58, 1100-1124.

19. Tcharkhtchi, A.; Lucas, A.S.; Trotignon, J.P.; Verdu, J. Viscoelastic properties of epoxy networks in the glass transition region. Polymer 1998, 39, 1233-1235.

20. Prisacariu, C. Perspectives: Novel crosslinked polyurethanes as shape-memory materials. In Polyurethane Elastomers; Prisacariu, C., Ed.; Springer-Verlag: Wien, Austria, 2011; pp 219-229.

21. Zhang, H.; Wang, H.; Zhong, W.; Du, Q. A novel type of shape memory polymer blend and the shape memory mechanism. Polymer 2009, 50, 1596-1601. 
22. Pittini, Y.Y.; Daneshvari, D.; Pittini, R.; Vaucher, S.; Rohr, L.; Leparoux, S.; Leuenberger, H. Cole-cole plot analysis of dielectric behavior of monoalkyl ethers of polyethylene glycol $\left(\mathrm{C}_{n} \mathrm{E}_{m}\right)$. Eur. Polym. J. 2008, 44, 1191-1199.

23. Merdas, I.; Thominette, F.; Tcharkhtchi, A.; Verdu, J. Factors governing water absorption by composite matrices. Compos. Sci. Technol. 2002, 62, 487-492.

24. Tcharkhtchi, A.; Bronnec, P.Y.; Verdu, J. Water absorption characteristics of diglycidylether of butane diol-3,5-diethyl-2,4-diaminotoluene networks. Polymer 2000, 41, 5777-5785.

25. Tcharkhtchi, A.; Gouin, E.; Verdu, J. Thermal expansion of epoxide-amine networks in the glassy state. J. Polym. Sci. B 2000, 38, 537-543.

26. Farzaneh, S.; Fitoussi, J.; Lucas, A.; Bocquet, M.; Tcharkhtchi, A. Shape memory effect and properties memory effect of polyurethane. Appl. Polym. Sci. 2013, 128, 3240-3249.

27. Bhatia, A.; Gupta, R.; Bhattacharya, S.; Choi, H. Compatibility of biodegradable poly(lactic acid) (PLA) and poly(butylene succinate) (PBS) blends for packaging application. Korea-Aust. Rheol. J. 2007, 19, 125-131.

28. Harada, M.; Ohya, T.; Iida, K.; Hayashi, H.; Hirano, K.; Fukuda, H. Increased impact strength of biodegradable poly(lactic acid)/poly(butylene succinate) blend composites by using isocyanate as a reactive processing agent. J. Appl. Polym. Sci. 2007, 106, 1813-1820.

29. NF ISO 6239:1986. Plastics-Determination of Tensile Properties by Use of Small Specimens. Association Française de Normalisation (AFNOR): Seine-Saint-Denis, France, 1986.

(C) 2014 by the authors; licensee MDPI, Basel, Switzerland. This article is an open access article distributed under the terms and conditions of the Creative Commons Attribution license (http://creativecommons.org/licenses/by/3.0/). 